\title{
Theoretical and Empirical Analysis of Market-Power Adjusted RIM Model
}

\author{
Lixia Wang ${ }^{1} \&$ Lining Gan $^{1}$ \\ ${ }^{1}$ SHU-UTS SILC Business School, Shanghai University, China \\ Correspondence: Lixia Wang, SHU-UTS SILC Business School, Shanghai University, No. 20 Cheng Zhong \\ Road, Jiading District, Shanghai, China. Tel: 86-21-6998-0028. E-mail: philipw3178@163.com
}

Received: December 12, 2015

Accepted: December 29, 2015 Online Published: January 25, 2016

doi:10.5539/ijef.v8n2p147

URL: http://dx.doi.org/10.5539/ijef.v8n2p147

\begin{abstract}
The market power of firms can take an important effect on their value through the influence of residual incomes. Based on Ohlson's residual income model (RIM model, also called EBO model), the paper puts financial account - unearned revenue to build the new model, market-power adjusted RIM model. Then we make empirical analysis using the data from 2003 to 2011 year in China capital market. The empirical evidence proofs that unearned revenue has an obvious effect on the value of firms. The result shows that the new model has important complementary role to evaluate the firms' value in China capital market.
\end{abstract}

Keywords: market position, RIM model, unearned revenue

\section{Introduction}

Since 1991 capital market was introduced in China, it has made great achievements after 20 years' development. At present, China's capital market scale has reached top 2 in the world, the stock market value of capital market has become one of the core elements of the development of the socialist market economy in China, as well as the main driving force of optimizing the allocation of resources. Thus, scholars' study of China's capital market has been going on, the value of the overseas capital market in China and applicability of valuation theory research, based on China's capital market specific design valuation model also emerge in endlessly. The main typical valuation model and method are the discounted cash flow method (DCF), discounted dividend model (DDM), capital asset pricing model (CAPM), relative valuation method (PE), real option evaluation method and residual income model (RIM).

However, in China, market power has a significant impact on the development of the company. Enterprises of high market position, can obtain more advantage of the market competition in China than those of lower market position, and produce more of the excess profit, the theories mentioned above is not completely adaptable.

In general, the higher the market position of the enterprise, the stronger the negotiation is. In turn, it can in advance collect unearned revenue from customers. On the contrary, the lower the market position of the enterprise, the more difficult it will be to charge to the customer, even the more accounts receivable and bad debt is. Accordingly, based on the Olhson's residual income model, this paper focuses on the study how to affect evaluation of company about market position factors which reflect on the financial account--unearned revenue.

\section{Literature Review}

Unearned revenue is a kind of debt term in the contract between the seller and the buyer, paid in advance from buyers to sellers. In the market economy environment, enterprises possessing more unearned revenue show that they have the monopoly position in their industry or resource advantages. Manufacturing companies particularly having a large amount of unearned revenue mean that the products are in short supply. Under the condition of that the buyers take payment to the seller without goods received, the sellers of the product have a monopoly position in the market or a particular advantage.The company with the increasing amount of unearned revenue, to some degrees, reflects the company's industry status and competitiveness.Xinming Zhang (2012) argued that through the empirical study of Chinese capital market, high market power can obtain high commercial credit financing for the enterprises. Sanxian Chen (2004) referenced "future performance" to describe the anticipated function of unearned revenue, through the empirical study shows that the increase of unearned revenue indicates the growth of the company's performance. Bo Liu etc. (2009) showed the strong positive correlation between the 
unearned revenue and corporate performance of listed companies from the empirical research. Jifu Cai (2013), through the empirical analysis pointed out that obviously the unearned revenue of private enterprises is positively related to bank loan, and then put forward the market power affects the financial support. However, their studies fail to show the unearned revenue how to affect the value of the company's equity and so does the degree of its influence? Based on this, this paper will take unearned revenue as a factor into consideration to directly applied to the intrinsic evaluation of enterprises' valuation.

\section{Research Hypothesis and Model Building}

\subsection{Research Hypotheses and Propositions Put Forward}

\subsubsection{Hypothesis}

Unearned revenue per share of this period and the unearned revenue per share of the previous period have a fixed linear relationship, namely: $Y_{t+1}=m Y_{t}+\varepsilon_{t}$

Here:

$Y_{t+1}$ : is unearned revenue per share of the $(\mathrm{t}+1)$ th period;

$Y_{t}$ : is unearned revenue per share in the end of $\mathrm{t}$ th period;

$\varepsilon_{t}$ : is a random variable with zero mean;

$m$ : is coefficient, as a known constant.

This assumption is clear because the market power is continuing whose increase or decrease is an ongoing process. Therefore, there is a certain linear relationship between the adjacent years.

\subsubsection{Putting forward Proposition}

Based on the Hypothesis above, take the following two propositions:

Proposition 1: There is a positive correlation relationship between the unearned revenue and the intrinsic value of company's equity. The model is:

$$
V a l_{t}=B V_{t}+\alpha X_{t}+\beta Y_{t}+\gamma U_{t}
$$

In the formula:

$\mathrm{Val}_{t}$ : is the equity value per share in the $\mathrm{t}^{\text {th }}$ period for the company;

$B V_{t}$ : is the book value per share in the $\mathrm{t}^{\text {th }}$ period for the company;

$X_{t}$ : is residual income per share in the $\mathrm{t}^{\text {th }}$ period for the company;

$Y_{t}$ : is unearned revenue per share in the end of $\mathrm{t}^{\text {th }}$ period;

$U_{t}:$ are other factors that influence the equity value per share in the $\mathrm{t}^{\text {th }}$ period for the company;

$\alpha, \beta, \gamma$ : are coefficients, as known constant respectively.

Proposition 2: although intrinsic value of company's equity is positively correlated with the unearned revenue, it is negative correlated with unearned revenue per share's quadratic, namely there is a maximum, inverted $u$-shaped relationship. The model is:

$$
\operatorname{Val}_{t}=B V_{t}+\alpha X_{t}+\beta_{1} Y_{t}+\beta_{2} Y_{t}^{2}+\gamma U_{t}
$$

In the formula:

$\beta_{1}, \beta_{2}$ are respectively coefficients of unearned revenue per share $Y_{t}, Y_{t}^{2}$, as known constant, $Y_{t}^{2}$ is unearned revenue per share's quadratic;

Other letters represent the same meanings of formula (1) .

\subsection{Reasoning and Theoretical Basis of the Model}

Ohlson (1995) Put forward the following residual income model of calculating the intrinsic value of company's equity :

$$
\begin{aligned}
V a l_{t} & =B V_{t}+\sum_{\tau=1}^{\infty} R_{f}^{-\tau} E_{t}\left[X_{t+\tau}\right] \\
X_{t+1} & =\omega X_{t}+v_{t}+\varepsilon_{1 t+1}
\end{aligned}
$$




$$
v_{t+1}=\varphi v_{t}+\varepsilon_{2 t+1}
$$

In the formula:

$E\left[X_{t+\tau}\right]:$ is the expected value of residual income in the $t+\tau$ th period

$R_{f}$ : is risk discount rate, equal to 1 plus free-risk rate, namely: $R_{f}=1+\mathrm{r}$;

$\omega, \varphi$ : is coefficient, as a known constant;

Other letters represent the same meanings above.

Based on the assumptions proposed in this paper, formula (3) can be shown as the following formula (4) and formula (5):

Based on the proposition 1:

$$
\begin{gathered}
V a l_{t}=B V_{t}+\sum_{\tau=1}^{\infty} R_{f}^{-\tau} E_{t}\left[X_{t+\tau}\right] \\
X_{t+1}=\omega X_{t}+\xi Y_{t}+v_{t}+\varepsilon_{1 t+1} \\
Y_{t+1}=m Y_{t}+\varepsilon_{2 t+1} \\
v_{t+1}=\varphi v_{t}+\varepsilon_{3 t+1}
\end{gathered}
$$

Based on the proposition 2:

$$
\begin{gathered}
V a l_{t}=B V_{t}+\sum_{\tau=1}^{\infty} R_{f}^{-\tau} E_{t}\left[X_{t+\tau}\right] \\
X_{t+1}=\omega X_{t}+\xi_{1} Y_{t}+\xi_{2} Y_{t}^{2}+v_{t}+\varepsilon_{1 t+1} \\
Y_{t+1}=m Y_{t}+\varepsilon_{2 t+1} \\
v_{t+1}=\varphi v_{t}+\varepsilon_{3 t+1}
\end{gathered}
$$

In the formula:

$\xi, \xi_{1}, \xi_{2}:$ are parameters' coefficients respectively, as known constants.

Other letters represent the same meanings above.

$\omega, m$ and $\varphi$ are respectively residual income, market power and persistence of other information, which can only range between 0 and 1 , mainly because of :

1) Mathematical reason: only $\omega, m$ and $\varphi$ range between 0 and 1, can formula (3), formula (4) and formula (5) converged, Ohlson (1995) and Feltham and Ohlson (1995) are also based on this.

2) Economic reason: for the long time, with the updating of both technology and products, the increasing of the competition and new entrants, the companies' residua income, market power and so on are unlikely continue to increase or strengthened.

3) Practical reason: for the long time, despite of not the full influence, in practice the residual income、 market power and other factors in the current period will take effect of those of the next period. It is realistic to have linear relationship during the adjacent periods.

Based on reasons above, put formula (4) and formula (5) respectively into formula (3), then it can obtain the following formula (6) and formula (7):

$$
\begin{aligned}
& \operatorname{Val}_{t}=B V_{t}+\alpha X_{t}+\beta Y_{t}+\gamma U_{t} \\
& \alpha=\frac{1}{R_{f}-\omega} \\
& \beta=\frac{R_{f} \xi}{\left(R_{f}-\omega\right)\left(R_{f}-m\right)} \\
& \gamma=\frac{R_{f} \varphi}{\left(R_{f}-\omega\right)\left(R_{f}-\varphi\right)}
\end{aligned}
$$




$$
\begin{aligned}
& V a l_{t}=B V_{t}+\alpha X_{t}+\beta_{1} Y_{t}+\beta_{2} Y_{t}^{2}+\gamma U_{t} \\
& \alpha=\frac{1}{R_{f}-\omega} \\
& \beta_{1}=\frac{R_{f} \xi_{1}}{\left(R_{f}-\omega\right)\left(R_{f}-m\right)} \\
& \beta_{2}=\frac{R_{f} \xi_{2}}{\left(R_{f}-\omega\right)\left(R_{f}-m^{2}\right)} \\
& \gamma=\frac{R_{f} \varphi}{\left(R_{f}-\omega\right)\left(R_{f}-\varphi\right)}
\end{aligned}
$$

Formula (6) above deduces proposition one theoretically, namely formula (1), formula (7) above deduces proposition two theoretically, namely formula (2).

\subsection{The Set of the Empirical Model}

In practice, because other factors can't be described by quality, for other factors of formula (6) and formula (7) above, namely variable $U_{t}$, in the actual empirical research, this paper references methods proposed by Myers (1999) on the empirical research, namely ignoring "other information", and add an intercept. it is an equivalent conversion in mathematics. Thus, the formula (6) and formula (7) above can be converted into the following empirical models respectively:

$$
\begin{aligned}
& \mathrm{Val}_{t}=\alpha_{0}+B V_{t}+\alpha X_{t}+\beta Y_{t} \\
& \alpha=\frac{1}{R_{f}-\omega} \\
& \beta=\frac{R_{f} \xi}{\left(R_{f}-\omega\right)\left(R_{f}-m\right)} \\
& \operatorname{Val}_{t}=\alpha_{0}+B V_{t}+\alpha X_{t}+\beta_{1} Y_{t}+\beta_{2} Y_{t}^{2} \\
& \alpha=\frac{1}{R_{f}-\omega} \\
& \beta_{1}=\frac{R_{f} \xi_{1}}{\left(R_{f}-\omega\right)\left(R_{f}-m\right)} \\
& \beta_{2}=\frac{R_{f} \xi_{2}}{\left(R_{f}-\omega\right)\left(R_{f}-m^{2}\right)}
\end{aligned}
$$

In the formula:

$\alpha_{0}$ is intercept coefficient, other letters represent the same meanings above.

\section{The Empirical Test}

\subsection{Forecast Ranges of the Correlation Coefficient}

Based on the practical significance of the accounting, all kinds of predicted ranges of the correlation coefficient are:

\begin{tabular}{cc}
\hline coefficient & value range \\
\hline$\omega$ & {$[0,1]$} \\
$m$ & {$[0,1]$} \\
$\varphi$ & {$[0,1]$} \\
$\alpha$ & {$[0,+\infty)$} \\
$\beta$ & {$[0,+\infty)$} \\
$\beta_{1}$ & {$[0,+\infty)$} \\
$\beta_{2}$ & {$[-\infty, 0]$} \\
\hline
\end{tabular}

Therefore, based on the formula (8) and formula (9) above, we can use real financial data of listed companies to 
calculate its theoretical value. In efficient markets, based on the efficient market hypothesis, the price of the stock of capital market is a reflection of its intrinsic value, at the same time, in the empirical research of equity value judgment, scholars are assuming that the price of the stock is its value. A large number of empirical studies also show it exists certain linear relationship between the company's stock price and value, namely $P_{t}=c_{0}+c_{1} V_{a l}+\varepsilon_{t} \cdot\left(c_{0}, c_{1}\right.$ are known coefficient). Thus, in this paper, the following empirical study also uses the same method, namely the price of the stock $P$ takes place of intrinsic value Val on the left of the formula above.

\subsection{Variable Definitions and Data Explanations}

The empirical data referred to in this paper, comes from WIND database to consolidate corresponding annual data (annual report). In this paper calculation method and explanation of each variable are as follows:

$\mathrm{P}:$ is price of per share (no restoration of rights).

$\mathrm{BV}$ : is book value of equity per share on the date of balance sheet, which contains minority's interest.

EPS: is earning per share, namely, net profit of the $\mathrm{t}^{\text {th }}$ period / total stock shares in the end of the $\mathrm{t}^{\text {th }}$ period

$R_{f}$ : is 1 plus the risk-free rate of return $\mathrm{r}$, particularly $\mathrm{r}$ is calculated with a one-year fixed bank deposit interest rate.

$X$ : is residual income per share, which is equal to the net profit of certain period subtract book value of equity at beginning period times the risk-free rate of return, namely: residual income per share of the th period $=$ net profit of the $\mathrm{t}^{\text {th }}$ period - $\mathrm{r} *$ equity of the $(\mathrm{t}-1)^{\text {th }}$ period

This article selects all manufacturing listed companies in Shanghai and Shenzhen between 2003 and 2011 as empirical research object, the empirical use of relevant financial data and stock market prices are all from Wind database system. According to the regulation, the annual reports of listed companies must be disclosed before the April 30th next year, therefore this article selects closing price on April 30th every year as required for the empirical research. If that day will be closed for holiday, closing price on the previous trading day is selected as the calculation basis.

\subsection{Samples Selection and Variable Description}

\subsubsection{Samples Selection}

See the following Table 1 .

Table 1. Samples selection

\begin{tabular}{lllllllllll}
\hline Manufacturing companies & Year & Year & Year & Year & Year & Year & Year & Year & Year & Total \\
& 2003 & 2004 & 2005 & 2006 & 2007 & 2008 & 2009 & 2010 & 2011 & \\
\hline Subtract: STPT & 752 & 820 & 821 & 873 & 943 & 977 & 1030 & 1188 & 1275 & 8679 \\
& -45 & -51 & -46 & -57 & -76 & -56 & -41 & -61 & -55 & -508 \\
Subtract: lack of price & 707 & 769 & 775 & 816 & 867 & 921 & 989 & 1127 & 1220 & 8191 \\
& -41 & -54 & -68 & -77 & -45 & -51 & -75 & -48 & -60 & -529 \\
Subtract:lack of the book value & 656 & 715 & 707 & 739 & 822 & 870 & 914 & 1079 & 1160 & 7662 \\
& -43 & -68 & -9 & -57 & -81 & -41 & -75 & -83 & -111 & -671 \\
Subtract: lack of ultimately controllers & 613 & 647 & 698 & 682 & 741 & 826 & 839 & 896 & 1049 & 6991 \\
& 0 & 0 & 0 & 0 & 0 & 0 & -2 & -2 & -3 & -7 \\
Samples & 613 & 647 & 698 & 682 & 741 & 826 & 837 & 894 & 1046 & 6984 \\
\hline
\end{tabular}

Note. STPT is "ST" enterprise, which references loss in past two years.

\subsubsection{Descriptive Statistical Analysis of the Variables}

See the following Table 2: 
Table 2. Descriptive statistical analysis of the variables

\begin{tabular}{lllllll}
\hline & & price & BV & $X$ & Y & Y2 \\
\hline Year 2003 & Mean & 8.343 & 3.286 & 0.149 & 0.210 & 0.258 \\
& Median & 7.320 & 3.111 & 0.102 & 0.075 & 0.006 \\
Year 2004 & Mean & 5.186 & 3.229 & 0.113 & 0.272 & 0.785 \\
& Median & 4.170 & 3.053 & 0.087 & 0.088 & 0.008 \\
Year 2005 2006 & Mean & 5.946 & 3.261 & 0.086 & 0.266 & 0.626 \\
& Median & 4.525 & 3.100 & 0.077 & 0.097 & 0.009 \\
Year 2007 & Mean & 15.397 & 3.145 & 0.170 & 0.294 & 0.674 \\
& Median & 12.170 & 2.990 & 0.088 & 0.111 & 0.012 \\
Year 2008 & Mean & 14.489 & 3.627 & 0.267 & 0.366 & 1.561 \\
& Median & 10.930 & 3.363 & 0.148 & 0.119 & 0.014 \\
Year 2009 & Mean & 11.045 & 3.356 & 0.186 & 0.360 & 2.621 \\
& Median & 8.590 & 3.130 & 0.102 & 0.100 & 0.010 \\
Year 2010 & Mean & 15.585 & 3.651 & 0.270 & 0.400 & 3.062 \\
& Median & 12.690 & 3.291 & 0.148 & 0.114 & 0.013 \\
Year 2011 & Mean & 17.624 & 4.120 & 0.336 & 0.399 & 1.531 \\
& Median & 14.160 & 3.603 & 0.208 & 0.113 & 0.013 \\
& Mean & 12.778 & 4.649 & 0.290 & 0.360 & 1.171 \\
\hline & Median & 10.095 & 3.978 & 0.152 & 0.112 & 0.013 \\
& Mean & 12.192 & 3.663 & 0.218 & 0.333 & 1.438 \\
\hline
\end{tabular}

Easily found from Table 2, the mean and median of the company's share price are showing a trend: rise after down first, and then down and up, at last drop. During the period it shows obvious fluctuation. Besides compared with the mean, at the same time every year, the median are smaller than the mean, showing apparent left-skewed. The mean and the median of company's book value of equity do not have this wave phenomenon like stock price, it keeps rising for the long term. Unearned revenue per share has little change, the mean peak appeared in 2009, this may be due to the financial crisis of 2008 , leading to charge more unearned revenue for enterprises to avoid risk.

4.4 The Empirical Test Results

4.4.1 Empirical Test Results of Proposition 1

See the following Table 3:

Table 3. Annual regression results

\begin{tabular}{llllll}
\hline & Year 2003 & Year 2004 & Year 2005 & Year 2006 & Year 2007 \\
\hline Intercept & 5.08447 & 2.22048 & 2.30601 & 7.72334 & 6.84717 \\
& $(<.0001) * * *$ & $(<.0001) * * *$ & $(<.0001) * * *$ & $(<.0001) * * *$ & $(<.0001) * * *$ \\
$\mathrm{BV}$ & 0.73911 & 0.76628 & 0.91578 & 1.6398 & 1.00412 \\
& $(<.0001) * * *$ & $(<.0001) * * *$ & $(<.0001) * * *$ & $(<.0001) * * *$ & $(<.0001) * * *$ \\
$\mathrm{X}$ & 5.14348 & 3.23342 & 5.21368 & 12.33416 & 14.65218 \\
& $(<.0001) * * *$ & $(<.0001) * * *$ & $(<.0001) * * *$ & $(<.0001) * * *$ & $(<.0001) * * *$ \\
Y & 0.29454 & 0.46688 & 0.77902 & 1.43755 & 0.24124 \\
Observation value & -0.2628 & $(0.0011) * * *$ & $(0.001) * * *$ & $(0.0005) * * *$ & -0.4051 \\
F & 613 & 647 & 698 & 682 & 741 \\
Adjusted R2 & $138.82 * * *$ & $110.18 * * *$ & $109.69 * * *$ & $149.18 * * *$ & $237.01 * * *$ \\
\hline
\end{tabular}

Note. P-test statistics are shown in brackets; *** is $1 \%$ significance level; ** is $5 \%$ significance level; * is $10 \%$ significance level. 
Table 3. Annual regression results (continued)

\begin{tabular}{llllll}
\hline & Year 2008 & Year 2009 & Year 2010 & Year 2011 & Total Sample \\
\hline \multirow{2}{*}{ Intercept } & 5.34684 & 8.76034 & 8.18261 & 4.57667 & 5.55576 \\
& $(<.0001) * * *$ & $(<.0001) * * *$ & $(<.0001) * * *$ & $(<.0001) * * *$ & $(<.0001) * * *$ \\
$\mathrm{BV}$ & 1.25971 & 1.08991 & 1.05886 & 1.12806 & 1.14063 \\
& $(<.0001) * * *$ & $(<.0001) * * *$ & $(<.0001) * * *$ & $(<.0001) * * *$ & $(<.0001) * * *$ \\
$\mathrm{X}$ & 6.43685 & 10.05051 & 15.13675 & 9.26525 & 10.41351 \\
& $(<.0001) * * *$ & $(<.0001) * * *$ & $(<.0001) * * *$ & $(<.0001) * * *$ & $(<.0001) * * *$ \\
Y & 0.76913 & 0.31887 & -0.00226 & 0.7591 & 0.57125 \\
Observation value & $(<.0001) * * *$ & $(0.0444) * *$ & -0.9941 & $(0.0057) * * *$ & $(<.0001) * * *$ \\
F & 826 & 837 & 894 & 1046 & 6984 \\
Adjusted R2 & $279.02 * * *$ & $251.31 * * *$ & $275.72 * * *$ & $318.13 * * *$ & $1714.62^{* * * *}$ \\
\hline
\end{tabular}

Note. P-test statistics are shown in brackets; *** is $1 \%$ significance level; ** is $5 \%$ significance level; * is $10 \%$ significance level.

It can be found from Table 3, from 2003 to 2011, a total of nine years, unearned revenue reflecting the market power were statistical significant for 6 years, and all the samples are statistical significant. The reason for the statistics not significant in 2007 may be due to the influence of adopting the new accounting principle system, and the reasons for statistics not significant in 2010, which can be found from the stock price of this year, is that there may be a certain stock market bubble in 2010 when the mean of the stock price is the highest. Overall, it can be concluded from Table 3 that the unearned revenue reflecting the market power has a positive impact on the companies' equity value. Through testing the adaptability of model in the capital market in China built by formula (8), the proposition 1 is validated.

\subsubsection{Empirical Test Results of Proposition 2}

See the following Table 4.

Table 4. Annual regression results

\begin{tabular}{llllll}
\hline & Year 2003 & Year 2004 & Year 2005 & Year 2006 & Year 2007 \\
\hline Intercept & 5.15069 & 2.2148 & 2.26445 & 7.59956 & 6.74273 \\
& $(<.0001) * * *$ & $(<.0001) * * *$ & $(<.0001) * * *$ & $(<.0001) * * *$ & $(<.0001) * * *$ \\
BV & 0.7442 & 0.74064 & 0.87716 & 1.57978 & 0.93586 \\
& $(<.0001) * * *$ & $(<.0001) * * *$ & $(<.0001) * * *$ & $(<.0001) * * *$ & $(<.0001) * * *$ \\
$\mathrm{X}$ & 5.16877 & 3.18236 & 5.18606 & 12.34798 & 14.64624 \\
& $(<.0001) * * *$ & $(<.0001) * * *$ & $(<.0001) * * *$ & $(<.0001) * * *$ & $(<.0001) * * *$ \\
Y & -0.33306 & 0.92444 & 1.68155 & 2.93523 & 1.47525 \\
& -0.4916 & $(0.0025) * * *$ & $(0.0009) * * *$ & $(0.0006) * * *$ & $(0.0155) * *$ \\
Y2 & 0.17514 & -0.03847 & -0.11172 & -0.19324 & -0.06297 \\
& -0.1232 & $(0.0891) *$ & $(0.044) * *$ & $(0.0443) * *$ & $(0.0213) * *$ \\
Observation value & 613 & 647 & 698 & 682 & 741 \\
F & $104.95 * * *$ & $83.6 * * *$ & $83.65 * * *$ & $113.41 * * *$ & $180.13 * * *$ \\
Adjusted R2 & 0.4045 & 0.3384 & 0.3217 & 0.3977 & 0.4919 \\
\hline
\end{tabular}

Note. P-test statistics are shown in brackets; $* * *$ is $1 \%$ significance level; $* *$ is $5 \%$ significance level; * is $10 \%$ significance level. 
Table 4. Annual regression results (continued)

\begin{tabular}{llllll}
\hline & Year 2008 & Year 2009 & Year 2010 & Year 2011 & Total sample \\
\hline Intercept & 5.35225 & 8.77824 & 8.14332 & 4.42149 & 5.5341 \\
& $(<.0001) * * *$ & $(<.0001) * * *$ & $(<.0001) * * *$ & $(<.0001) * * *$ & $(<.0001) * * *$ \\
BV & 1.26843 & 1.09795 & 1.0511 & 1.10273 & 1.13236 \\
& $(<.0001) * * *$ & $(<.0001) * * *$ & $(<.0001) * * *$ & $(<.0001) * * *$ & $(<.0001) * * *$ \\
X & 6.45518 & 10.07268 & 15.07765 & 9.09671 & 10.37188 \\
& $(<.0001) * * *$ & $(<.0001) * * *$ & $(<.0001) * * *$ & $(<.0001) * * *$ & $(<.0001) * * *$ \\
Y & 0.63245 & 0.15038 & 0.30423 & 1.96141 & 0.79447 \\
& $(0.0506) *$ & -0.7027 & -0.6061 & $(<.0001)$ & $(<.0001) * * *$ \\
Y2 & 0.00426 & 0.00462 & -0.02029 & -0.09493 & -0.00931 \\
Observation value & 826 & -0.6405 & -0.5438 & $(0.0043) * * *$ & $(0.0852) *$ \\
F & -0.6456 & 837 & 894 & 1046 & 6984 \\
Adjusted R2 & $209.12 * * *$ & $188.36 * * *$ & $206.74 * * *$ & $242.29 * * *$ & $1287.07 * * *$ \\
\hline
\end{tabular}

Note. P-test statistics are shown in brackets; $* * *$ is $1 \%$ significance level; $* *$ is $5 \%$ significance level; * is $10 \%$ significance level.

It can be found from Table 4, unearned revenue reflecting the market power does exists extreme value for the influence of the value of equity of the company. From 2003 to 2011, a total of nine years, the coefficients of unearned revenue's quadratic except for year 2003, 2008, 2009, were negative, and were not statistically significant, at the same time, all the samples are statistically significant. In general, it can be concluded from Table 4, the unearned revenue reflecting the market power has a positive impact on the companies' value of equity, and there is extreme value, which is inverted u-shaped relationship, Through testing the adaptability of model in the capital market in China built by formula (9), the proposition 2 is validated.

\subsection{Robustness Testing}

Further analysis of the empirical results of proposition 1 and proposition 2 with different ultimately controller for listed companies, the results in the following Table 5:

Table 5. Empirical results according to different ultimately controllers

\begin{tabular}{lllll}
\hline & \multicolumn{2}{c}{ Non-state control } & \multicolumn{2}{c}{ State control } \\
\hline Intercept & 6.40404 & 6.32284 & 5.35443 & 5.31531 \\
$\mathrm{BV}$ & $(<.0001) * * *$ & $(<.0001) * * *$ & $(<.0001)^{* * * *}$ & $(<.0001) * * *$ \\
$X$ & 1.24514 & 1.23888 & 1.02544 & 1.0083 \\
& $(<.0001)^{* * *}$ & $(<.0001) * * *$ & $(<.0001)^{* * *}$ & $(<.0001)^{* * *}$ \\
$\mathrm{Y}$ & 7.86411 & 7.82753 & 11.84347 & 11.74678 \\
& $(<.0001) * * *$ & $(<.0001) * * *$ & $(<.0001) * * *$ & $(<.0001) * * *$ \\
$\mathrm{Y}^{2}$ & 0.1727 & 0.84085 & 0.60049 & 0.98152 \\
& $(0.4292)$ & $(0.0489) * *$ & $(<.0001) * * *$ & $(<.0001)^{* * *}$ \\
& & -0.08885 & & -0.01416 \\
Observation value & 2689 & $(0.0686) *$ & & $(0.0219) * *$ \\
$\mathrm{~F}$ & $493.4 * * *$ & 2689 & 4295 & 4295 \\
Adjusted $\mathrm{R}^{2}$ & 0.3547 & $371.2 * * *$ & $1229.74 * * *$ & $924.54 * * *$ \\
\hline
\end{tabular}

Note. P-test statistics are shown in brackets; $* * *$ is $1 \%$ significance level; $* *$ is $5 \%$ significance level; * is $10 \%$ significance level.

(1) For samples, using $1 \%$ shrinkage, the conclusion has not changed.

(2) For net profit per share, using indicator net profits this period / the latest stock shares, the conclusion has not changed.

(3) For the risk-free interest rate, replaced by the rate of return on treasury bonds at one year end, the conclusion has not changed. 


\section{Conclusion and Limitation}

\subsection{Conclusion}

It has always been the focus of investors to mine financial or non-financial information which is useful for companies' value of equity. This paper, on the basis of Ohlson's model, and through the strict mathematical reasoning, builds a valuation models which is suitable for Chinese market environment, and checked by Chinese capital market, it can draw the following conclusions:

Unearned revenue reflecting the market power information will directly has effect on companies' intrinsic value of equity, and the effect is positive.

Although market power can directly has positive effect on companies' intrinsic value of equity, its influence is not unlimited, there is a extreme value, namely the relationship between a company's equity value and unearned revenue is inverted $\mathrm{u}$-shaped relationship.

The theoretical and empirical analysis of market-power adjusted RIM model can be used to supplement the existing valuation models. It is also an effective means of valuation, and could be beneficial for investors to use financial or non-financial information adequately and make the right investing decisions.

\subsection{Limitation}

From the empirical analysis results, it can be found that not all the years' results are statistical significant.There may be other factors but not be found, it is also possible that assumptions of the model proposed in this paper are incomplete, such as failing to consider the company's investment condition, because the company's capital investment will affect company's periods of current and future, namely it should be considered from dynamic rather than only consider the static in this paper. These limitations will be one of the important content of the author's follow-up studies.

\section{References}

Bo, L., Shengdao, G., \& Yan, Z. (2009). Empirical Research of the Relationship of Unearned Revenue with Corporate Performance of Listed Companies. Modern Management Science, (8), 29-31.

Feltham, G., \& Ohlson, J. (1995). Valuation and Clean Surplus Accounting for Operating and Financial $\begin{array}{llll}\text { Activities. } & \text { Contemporary Accounting }\end{array}$ http://dx.doi.org/10.1111/j.1911-3846.1995.tb00462.x

Feltham, G., \& Ohlson, J. (1996). Uncertainty Resolution and the Theory of Depreciation Measurement. Journal of Accounting Research, 34(2), 209-234. http://dx.doi.org/10.2307/2491500

Jifu, C. (2013). Political Relations, Bank Loans and Commercial Credit Financing of Private Enterprises. Jiangxi University of Finance and Economics Journals, (3), 7-19.

Myers, J. N. (1999). Implementing Residual Income Valuation with Linear Information Dynamics. The Accounting Revies, 74(1), 1-28. http://dx.doi.org/10.2308/accr.1999.74.1.1

Ohlson, J. A. (1990). Synthesis of Security Valuation Theory and the Role of Dividends, Cash Flows and Earnings. Contemporary Accounting Research, (V7), 648-676. http://dx.doi.org/10.1111/j.1911-3846.1990.tb00780.x

Ohlson, J. A. (1995). Earnings, Book Values and Dividends in Equity Valuation. Contemporary Accounting Research, 11(2), 661-687. http://dx.doi.org/10.1111/j.1911-3846.1995.tb00461.x

Sanxian, C. (2004). Unearned Revenue--future performance. China Securities Journal, (4).

Xinmin, Z., Jue, W., \& Jigao, Z. (2012). Market Power, Business Credit And Enterprises' Operating financing. Accounting Research Study, (8), 60-99.

\section{Copyrights}

Copyright for this article is retained by the author(s), with first publication rights granted to the journal.

This is an open-access article distributed under the terms and conditions of the Creative Commons Attribution license (http://creativecommons.org/licenses/by/3.0/). 